\title{
Omega-3 polyunsaturated fatty acids supplementation in patients with diabetes and cardiovascular disease risk: does dose really matter?
}

\author{
Alexander Tenenbaum ${ }^{1,2+}$ and Enrique Z. Fisman ${ }^{1 *+}$ (10)
}

\begin{abstract}
There is a vast disagreement in relation to the possible beneficial effects of omega-3 polyunsaturated fatty acids (omega-3 PUFA) supplementation in patients with diabetes and cardiovascular disease. The conflicting results between the various original studies and meta-analyses could be partially explained as a result of variable supplementation dosage and duration, either of which may modify the effects of omega-3 PUFA on cardio-metabolic biomarkers. Meta-analyses are limited usually by the inability to draw inferences regarding dosage, duration and the interaction of dosage and duration of omega-3 PUFA intake. Even so, almost all endpoints in the so-called "negative" meta-analyses leaned toward a trend for benefit with a near 10\% reduction in cardiovascular outcomes and a borderline statistical significance. Many trials included in these meta-analyses tested an insufficient daily dose of omega-3 PUFA of less than $1000 \mathrm{mg}$. Probably, the consistent cardiovascular effects of omega-3 PUFA supplements could be expected only with daily doses above $2000 \mathrm{mg}$.
\end{abstract}

Keywords: Atherogenesis, Cardiovascular risk reduction, Coronary artery disease, Dyslipidemia, Hypertriglyceridemia, Omega 3 supplements, Polyunsaturated fatty acids, Type 2 diabetes mellitus

\section{Main text}

There is a vast disagreement in relation to the possible beneficial effects of omega-3 polyunsaturated fatty acids (omega-3 PUFA) supplementation in patients with diabetes and cardiovascular disease. The divergences have been just fueled by two recently published meta-analyses establishing that omega-3 PUFA supplementation may not reduce the risk for cardiovascular events $[1,2]$. These negative conclusions are accompanied by a number of studies demonstrating no benefits from omega-3 PUFA supplementation on oxidative stress, inflammatory parameters, coagulation and metabolic status in patients

\footnotetext{
*Correspondence: zfisman@post.tau.ac.il

${ }^{\dagger}$ Alexander Tenenbaum and Enrique Z. Fisman contributed equally to this article

${ }^{1}$ Sackler Faculty of Medicine, Tel Aviv University, 6997801 Tel Aviv, Israel Full list of author information is available at the end of the article
}

with atherosclerotic vascular disease and type 2 diabetes mellitus (T2DM) [3, 4].

In sharp contrast, the largest, most comprehensive and contemporary meta-analysis of randomized controlled trials has shown that omega-3 PUFA supplementation produces favorable hypolipidemic effects, a reduction in pro-inflammatory cytokine levels and improvement in glycemia [5]. The positive conclusions are complemented by an impressive group of most of the latest studies, demonstrating beneficial effects of omega-3 PUFA supplementation on metabolism [6-9]. Sawada et al. validated the fact that one of the omega-3 PUFAs-eicosapentaenoic acid-corrected postprandial hypertriglyceridemia, hyperglycemia and insulin secretion ability. This amelioration of several metabolic abnormalities was accompanied by recovery of concomitant endothelial dysfunction in patients with impaired glucose metabolism and coronary artery disease (CAD) [6]. In patients with residual 
hypertriglyceridemia despite statin treatment, a combination of omega-3 PUFA and rosuvastatin produced a greater reduction of triglyceride and non-HDL-cholesterol than rosuvastatin alone [7]. Omega-3 PUFA supplementation attenuated the progression of albuminuria in subjects with T2DM and CAD [8].

Jacobo-Cejudo et al. found a beneficial effect of omega-3 PUFA supplementation on waist circumference, glucose, $\mathrm{Hb} 1 \mathrm{Ac}$, leptin and leptin/adiponectin ratio [9]. It is well established that T2DM is associated with hypertriglyceridemia as a major component of atherogenic dyslipidemia, which significantly increases cardiovascular disease risk [10-12]. Specifically, hepatic insulin resistance in T2DM patients is the main determinant of postprandial lipoprotein metabolism and hypertriglyceridemia [13]. Omega-3 PUFA intake has been widely indicated for treatment of hypertriglyceridemia, promoting reductions in hepatic triglyceride synthesis and accelerating triglyceride clearance [14-17]. The benefits of omega-3 PUFA intake in appropriate doses (above $2000 \mathrm{mg}$ daily) on serum triglyceride levels are well-documented and not a matter of debate. Theoretically, these favourable effects have a pathophysiological basis to be translated into cardiovascular benefits.

The conflicting results between the various original studies and meta-analyses could be partially explained as a result of variable supplementation dosage and duration, either of which may modify the effects of omega-3 PUFA on cardio-metabolic biomarkers [18]. Meta-analyses are limited usually by the inability to draw inferences regarding dosage, duration and the interaction of dosage and duration of omega-3 PUFA intake. Even so, almost all endpoints in the so-called "negative" metaanalyses leaned toward a trend for benefit with a near $10 \%$ reduction in cardiovascular outcomes and a borderline statistical significance. Many trials included in these meta-analyses tested an insufficient daily dose of omega-3 PUFA of less than $1000 \mathrm{mg}$. Probably, the consistent cardiovascular effects of omega-3 PUFA supplements could be expected only with daily doses above $2000 \mathrm{mg}$.

Hopefully, two ongoing randomized controlled trials, REDUCE-IT and STRENGTH, which are assessing a daily dose of omega-3 PUFA of $4000 \mathrm{mg}$ in addition to statins in patients with hypertriglyceridemia, have potential for a soon clarification of the current controversies [19].

\section{Abbreviations \\ CAD: coronary artery disease; PUFA: polyunsaturated fatty acids; T2DM: type 2} diabetes mellitus.

\section{Authors' contributions}

AT and EZF equally contributed in the conception and drafting of the article. Both authors read and approved the final manuscript.

\begin{abstract}
Author details
${ }^{1}$ Sackler Faculty of Medicine, Tel Aviv University, 6997801 Tel Aviv, Israel. ${ }^{2}$ Cardiac Rehabilitation Institute, Sheba Medical Center, 5265601 Tel Hashomer, Israel.
\end{abstract}

\section{Acknowledgements}

Not applicable.

Competing interests

The authors declare that they have no competing interests.

Availability of data and materials

Not applicable.

Consent for publication

Authors give full consent for publication.

Ethics approval and consent to participate

Not applicable.

Funding

Not applicable.

\section{Publisher's Note}

Springer Nature remains neutral with regard to jurisdictional claims in published maps and institutional affiliations.

Received: 23 August 2018 Accepted: 23 August 2018

Published online: 28 August 2018

References

1. Aung T, Halsey J, Kromhout D, et al. Associations of omega-3 fatty acid supplement use with cardiovascular disease risks. JAMA Cardiol. 2018;3:225-34

2. Abdelhamid AS, Brown TJ, Brainard JS, Biswas P, Thorpe GC, Moore $H J$, Deane KH, Al Abdulghafoor FK, Summerbell CD, Worthington HV, Song F, Hooper L. Omega-3 fatty acids for the primary and secondary prevention of cardiovascular disease. Cochrane Database of Syst Rev. 2018;7:CD003177. https://doi.org/10.1002/14651858.cd003177.pub3.

3. Fayh APT, Borges K, Cunha GS, Krause M, Rocha R, de Bittencourt PIH, Moreira JCF, Friedman R, da Silva Rossato J, Fernandes JR, et al. Effects of n-3 fatty acids and exercise on oxidative stress parameters in type 2 diabetic: a randomized clinical trial. J Int Soc Sports Nutr. 2018;15:18.

4. Poreba M, Mostowik M, Siniarski A, Golebiowska-Wiatrak R, Malinowski KP, Haberka M, Konduracka E, Nessler J, Undas A, Gajos G. Treatment with high-dose n-3PUFAs has no effect on platelet function, coagulation, metabolic status or inflammation in patients with atherosclerosis and type 2 diabetes. Cardiovasc Diabetol. 2017;16:50.

5. O'Mahoney LL, Matu J, Price OJ, Birch KM, Ajjan RA, Farrar D, Tapp R, West DJ, Deighton K, Campbell MD. Omega-3 polyunsaturated fatty acids favourably modulate cardiometabolic biomarkers in type 2 diabetes: a meta-analysis and meta-regression of randomized controlled trials. Cardiovasc Diabetol. 2018;17:98.

6. Sawada T, Tsubata H, Hashimoto N, Takabe M, Miyata T, Aoki K, Yamashita S, Oishi S, Osue T, Yokoi K, Tsukishiro Y, Onishi T, Shimane A, Taniguchi Y, Yasaka Y, Ohara T, Kawai H, Yokoyama M. Effects of 6-month eicosapentaenoic acid treatment on postprandial hyperglycemia, hyperlipidemia, insulin secretion ability, and concomitant endothelial dysfunction among newly-diagnosed impaired glucose metabolism patients with coronary artery disease. An open label, single blinded, prospective randomized controlled trial. Cardiovasc Diabetol. 2016;15:121.

7. Kim CH, Han KA, Yu J, Lee SH, Jeon HK, Kim SH, Kim SY, Han KH, Won K, Kim DB, Lee KJ, Min K, Byun DW, Lim SW, Ahn CW, Kim S, Hong YJ, Sung J, Hur SH, Hong SJ, Lim HS, Park IB, Kim IJ, Lee H, Kim HS. Efficacy and safety of adding omega-3 fatty acids in statin-treated patients with residual hypertriglyceridemia: ROMANTIC (Rosuvastatin-OMAcor iN residual hyperTrlglyCeridemia), a randomized, double-blind, and placebo-controlled trial. Clin Ther. 2018;40:83-94. 
8. Elajami TK, Alfaddagh A, Lakshminarayan D, Soliman M, Chandnani M, Welty FK. Eicosapentaenoic and docosahexaenoic acids attenuate progression of albuminuria in patients with type 2 diabetes mellitus and coronary artery disease. J Am Heart Assoc. 2017;6(7):e004740. https://doi. org/10.1161/jaha.116.004740.

9. Jacobo-Cejudo MG, Valdés-Ramos R, Guadarrama-López AL, PardoMorales RV, Martínez-Carrillo BE, Harbige LS. Effect of n-3 polyunsaturated fatty acid supplementation on metabolic and inflammatory biomarkers in type 2 diabetes mellitus patients. Nutrients. 2017;9(6):E573. https://doi. org/10.3390/nu9060573.

10. Jørgensen PG, Jensen MT, Biering-Sørensen T, Mogelvang R, Galatius S, Fritz-Hansen T, Rossing P, Vilsbø\|l T, Jensen JS. Cholesterol remnants and triglycerides are associated with decreased myocardial function in patients with type 2 diabetes. Cardiovasc Diabetol. 2016;15:137.

11. Klempfner R, Erez A, Sagit BZ, Goldenberg I, Fisman E, Kopel E, Shlomo $\mathrm{N}$, Israel A, Tenenbaum A. Elevated triglyceride level is independently associated with increased all-cause mortality in patients with established coronary heart disease: twenty-two-year follow-up of the bezafibrate infarction prevention study and registry. Circ Cardiovasc Qual Outcomes. 2016;9:100-8

12. Valensi P, Avignon A, Sultan A, Chanu B, Nguyen MT, Cosson E. Atherogenic dyslipidemia and risk of silent coronary artery disease in asymptomatic patients with type 2 diabetes: a cross-sectional study. Cardiovasc Diabetol. 2016;15:104.
13. Leon-Acuña A, Alcala-Diaz JF, Delgado-Lista J, Torres-Peña JD, LopezMoreno J, Camargo A, Garcia-Rios A, Marin C, Gomez-Delgado F, Caballero J, Van-Ommen B, Malagon MM, Perez-Martinez P, Lopez-Miranda J. Hepatic insulin resistance both in prediabetic and diabetic patients determines postprandial lipoprotein metabolism: from the CORDIOPREV study. Cardiovasc Diabetol. 2016;15:68.

14. Kris-Etherton PM, Harris WS, Appel LJ, American Heart Association. Nutrition C Fish consumption, fish oil, omega-3 fatty acids, and cardiovascular disease. Circulation. 2002;106:2747-57.

15. Shearer GC, Savinova OV, Harris WS. Fish oil- how does it reduce plasma triglycerides? Biochim Biophys Acta. 2012;1821:843-51.

16. Harris WS, Miller M, Tighe AP, Davidson MH, Schaefer EJ. Omega-3 fatty acids and coronary heart disease risk: clinical and mechanistic perspectives. Atherosclerosis. 2008;197:12-24.

17. Adkins Y, Kelley DS. Mechanisms underlying the cardioprotective effects of omega-3 polyunsaturated fatty acids. J Nutr Biochem. 2010;21:781-92.

18. Jump DB, Depner CM, Tripathy S. Omega-3 fatty acid supplementation and cardiovascular disease: thematic review series: new lipid and lipoprotein targets for the treatment of cardiometabolic diseases. J Lipid Res. 2012:53:2525-45.

19. Handelsman Y, Shapiro MD. Triglycerides, atherosclerosis, and cardiovascular outcome studies: focus on omega-3 fatty acids. Endocr Pract. 2017:23:100-12.
Ready to submit your research? Choose BMC and benefit from:

- fast, convenient online submission

- thorough peer review by experienced researchers in your field

- rapid publication on acceptance

- support for research data, including large and complex data types

- gold Open Access which fosters wider collaboration and increased citations

- maximum visibility for your research: over $100 \mathrm{M}$ website views per year

At BMC, research is always in progress.

Learn more biomedcentral.com/submissions 